\title{
O INGRESSO MÍNIMO VITAL NA ESTRUTURA DE PROTEÇÃO SOCIAL DA ESPANHA APÓS A PANDEMIA DE COVID-19 1
}

\section{THE MINIMUM VITAL INCOME IN SPAIN'S SOCIAL PROTECTION STRUCTURE AFTER THE COVID-19 PANDEMIC}

RESUMO: Antes mesmo do impacto causado pela pandemia de COVID-19, a estrutura de proteção social espanhola já era marcada por risco de pobreza, desemprego e desigualdade estruturais. O Estado não possuía em seu sistema de Seguridade Social uma política de garantia de renda à população mais vulnerável, tendo sido tal função desempenhada de forma heterogênea, fragmentada e insuficiente pelas Comunidades Autônomas no exercício de sua competência em matéria de assistência social. No início de 2020, tais elementos estruturais foram elevados a limites extremos, impulsionados pelas consequências das medidas de contenção à pandemia. Como resposta, foi publicado o Real Decreto-lei 20/2020, que estabelece o Ingresso Mínimo Vital, política destinada a garantir uma renda mínima à população em situação de vulnerabilidade econômica, paliando a pobreza extrema e redistribuindo renda. O presente estudo visa analisar os principais aspectos jurídicos do Real Decreto-lei 20/2020, à luz da Constituição Espanhola de 1978, considerando o seu impacto sobre a até então vigente estrutura de proteção social, e comparando-o com a alternativa de uma política de Renda Básica Universal. Constata-se que o Ingresso Mínimo Vital constitui significativo avanço na estrutura de proteção social espanhola, mas apresenta insuficiente cobertura e diferenciação de tratamento questionável sob a perspectiva constitucional.

Palavras-Chave: Ingresso Mínimo Vital; Renda Básica Universal; Proteção Social; COVID-19; Pobreza.

\footnotetext{
${ }^{1} \mathrm{O}$ presente estudo foi concluído e enviado aos organizadores da publicação em 08 de junho de 2020, motivo pelo qual não se consideram eventuais alterações normativas posteriores.

${ }^{2}$ Doutorando em Direito Constitucional pela Universidade de Oviedo, financiado pelo Programa de Apoio e Promoção da Pesquisa (Projeto PAPI-19-PF-01), do Vice-reitorado de Pesquisa da mesma instituição. E-mail: rocha@uniovi.es.
} 
ABSTRACT: Even before the impact caused by the COVID-19 pandemic, the Spanish social protection structure was already marked by structural risk of poverty, unemployment and inequality. The State did not have in its social security system a policy to guarantee income to the most vulnerable population, and this function was performed in a heterogeneous, fragmented and insufficient manner by the Autonomous Communities in the exercise of their competence in the area of social assistance. In early 2020, such structural elements were pushed to extreme limits, driven by the consequences of the measures to contain the pandemic. In response, Royal Decree-Law 20/2020 was published, establishing the Minimum Vital Income, a policy designed to guarantee a minimum income to the economically vulnerable population, alleviating extreme poverty and redistributing income. The present study aims to analyse the main legal aspects of the Royal Decree-Law 20/2020, under the light of the Spanish Constitution of 1978, considering its impacts on the previous social protection structure and comparing it with the alternative of a Universal Basic Income policy. It can be noticed that the Minimum Vital Income constitutes a significant advance in the Spanish social protection structure, but it presents insufficient coverage and a differentiation of treatment that is questionable under the constitutional perspective.

KEYWORDS: Minimum Vital Income; Universal Basic Income; Social Protection; COVID-19; Poverty.

Bernarda - Menos gritos y más obras. Debías haber procurado que todo esto estuviera más limpio para recibir al duelo. Vete. No es éste tu lugar. (La Criada se va sollozando) Los pobres son como los animales. Parece como si estuvieran hechos de otras sustancias.

Mujer 1 - Los pobres sienten también sus penas.

Bernarda - Pero las olvidan delante de un plato de garbanzos.

Muchacha 1 - (Con timidez) Comer es necesario para vivir.

(Federico García Lorca, La Casa de Bernarda Alba, 1936)

\section{INTRODUÇão}

A fragilidade da estrutura de proteção social espanhola não é algo novo, mas é especialmente sentida quando as instituições do Estado Social são testadas em seus limites, como na crise financeira iniciada em 2008, com duros efeitos até 2012, e agora volta a ser sob os impactos da pandemia de COVID-19, de consequências ainda incomensuráveis. Parecendo ignorar a presença estrutural do desemprego, escancarada pelo fato de que em 27 dos últimos 40 anos o país conviveu com uma 
taxa de desocupação superior a 15\% (INE, 2018b), assim como o fenômeno cada vez mais recorrente dos trabalhadores pobres e em situações precárias, Espanha mantém o trabalho, em especial seu exercício subordinado a terceiro, como principal eixo de sua estrutura de inserção e proteção social.

Alie-se a isto o fato de que a chamada IV Revolução Industrial, com a substituição progressiva do emprego de pessoas pelo uso de máquinas nas tarefas de trabalho, indica uma grande diminuição dos empregos remunerados nas próximas décadas. Estima-se que, em Espanha, até 36\% dos postos de trabalho hoje existentes estão em risco de automatização nas próximas duas décadas (DOMÉNECH et al., 2018, p. 13).

Consequentemente, as pessoas que não dispunham de riquezas acumuladas e, por diversos motivos, não alcançam remuneração suficiente por meio do emprego ou das prestações da Seguridade Social, até então majoritariamente derivadas de um modelo contributivo, viam-se obrigadas a buscar sua última rede de salvação em uma heterogênea estrutura de assistência social. $\mathrm{O}$ reflexo disto é que, mesmo após a atuação de toda a estrutura de proteção social, Espanha apresenta indicadores de uma pobreza encrustada como em seu tecido social.

O trabalho, elemento já instável na estrutura social, recebeu um forte golpe conjuntural causado pela pandemia de COVID-19. Os enormes furos da rede de proteção social tornaram-se ainda mais visíveis, sendo ela incapaz de impedir que um significativo número de indivíduos, em virtude da insegurança de seus rendimentos, entre na situação de risco de pobreza.

Frente a isto, a pauta do debate público foi tomada por diversos temas relacionados a políticas de garantia de rendas, como a Renda Mínima direcionada às pessoas mais economicamente vulneráveis, e a Renda Básica Universal (RBU). Após oscilar acerca de uma possível implementação de uma ajuda de caráter emergencial e temporário, o Governo de Espanha optou por acelerar o desenho e a implementação do Ingresso Mínimo Vital (IMV), uma política estatal permanente para assegurar uma renda mínima às famílias mais pobres, tal qual prevista no acordo de coalizão firmado em dezembro de 2019 entre o Partido Socialista Espanhol (PSOE) e Unidas Podemos, os dois principais partidos que viriam a formar o Governo em janeiro de 2020 (PSOE; UNIDAS PODEMOS, 2019, p. 15).

O presente estudo se dedica à análise dos principais aspectos jurídicos do Real Decreto-lei 20, de $1^{\text {o }}$ de junho de 2020, que estabelece o IMV como medida que integra o sistema estatal de Seguridade Social. Os pontos abordados terão como paradigma os preceitos constitucionais pertinentes, inclusive os princípios reitores da política social e econômica. Por fim, serão apresentados alguns elementos da proposta teórica da Renda Básica Universal (RBU) como principal ferramenta de uma estrutura de inserção e proteção social fundada na concepção constitucionalmente adequada de liberdade real da pessoa, como alternativa à vigente, construída em torno do trabalho. 


\section{DADOS DA POBREZA EM ESPANHA}

Conforme números de 2018, Espanha possuía 46,7 milhões de habitantes, dos quais $21,5 \%$ se encontram em situação de risco de pobreza (INE, 2019). Uma análise mais descuidada pode levar a crer que tal risco ronda apenas aqueles que, por diversas contingências, não conseguem se inserir no mercado laboral. Entretanto, um olhar mais atento expõe as mazelas de relações laborais inseguras e mal remuneradas, típicas daquilo que GUY STANDING (2014) alcunhou como precariado. Ainda conforme dados de 2018, 11,3\% das pessoas que trabalhavam em Espanha estavam em situação de risco de pobreza, sendo que $13,5 \%$ dos trabalhadores estavam em situação de exclusão social (FUNDACIÓN FOESSA, 2019, p. 141).

Já aqui se faz necessária uma observação para permitir a melhor compreensão dos dados. Assim como os demais países da União Europeia (UE), o Instituto Nacional de Estatísticas de Espanha (INE) adota um critério relativo de mensuração da desigualdade de renda na população, definindo como em risco de pobreza aquelas pessoas que vivam em lares que, mesmo após a transferência de benefícios, contem com menos de $60 \%$ da mediana nacional de renda disponível. Conforme o próprio Escritório de Estatísticas da UE (Eurostat) destaca, não se trata de um critério de medição de riqueza ou de pobreza (EUROSTAT, 2018b). Assim, mesmo os critérios complementares utilizados por outras instituições, partindo do critério da UE, ao final são critérios relativos, ainda que utilizem a denominação de linha de pobreza severa, como é o caso da Fundação Foessa, que classifica de pobreza moderada o critério utilizado pelo Eurostat e considera como em situação de pobreza severa aqueles que vivam em lares com renda disponível inferior a $30 \%$ da mediana nacional (FUNDACIÓN FOESSA, 2019, p. 576).

É importante que se tenha claro que o critério do Eurostat parte de uma lógica diferente da utilizada por aqueles países que, como o Brasil, adotam a metodologia desenhada pelo Banco Mundial, que estabelece três faixas absolutas de mensuração de pobreza, quais sejam, US\$1,90 (países de baixa renda), US\$3,20 (países de renda média baixa) e US\$ 5,50 (países de renda média alta) por dia, ajustados pela paridade do poder de compra (THE WORLD BANK, 2017).

Como referência para as considerações deste trabalho, frise-se que a linha de risco de pobreza em Espanha, para o ano de 2018, calculado com base nos rendimentos de 2017, era de $8.871 €$ anuais, o que equivale a aproximadamente 740 $€$ mensais (INE, 2018a). Além da pobreza e do desemprego estruturais, outro fator destacado na sociedade espanhola é a desigualdade. Conforme dados de 2018, o Índice de Gini no país era de 33,4, quase três pontos acima da média da União Europeia (EUROSTAT, 2018a).

Ainda em 2019, antes da pandemia, estudos já apontavam que as características do modelo de transição social adotado por Espanha nos últimos anos, por meio de uma recuperação econômica marcadamente excludente, caracterizavam não 
apenas um cenário pós-crise, mas também a prévia de uma nova crise social (FUNDACIÓN FOESSA, 2019, p. 23).

É neste contexto que a COVID-19 entra em cena. Desemprego e risco pobreza estruturais, mesmo após a aplicação das ferramentas vigentes de seguridade e assistência sociais, em um Estado regido pela Constituição Espanhola de 1978 (CE/78), que traz em seu artigo 1o o Estado Social como um de seus princípios estruturantes, o qual impõe a superação da dicotomia sociedade e Estado, por meio da atuação deste em relações tradicionalmente tidas como do âmbito daquela e em prestações em favor de indivíduos desfavorecidos (PRESNO LINERA, 2006, p. 40). O detalhamento desta fórmula constitucional encontra-se no artigo 9.2, segundo o qual:

Corresponde aos poderes públicos promover as condições para que a liberdade e a igualdade do indivíduo e dos grupos em que se integra sejam reais e efetivas; remover os obstáculos que impeçam ou dificultem sua plenitude e facilitar a participação de todos os cidadãos na vida política, econômica, cultural e social ${ }^{3}$.

Já em 14 de março de 2020, por meio do Real Decreto 463/2020, Espanha declara estado de alarme para gestão da situação de crise sanitária ocasionada pela COVID19. Tal situação sofreu 6 prorrogações, de modo que referido estado estendeu-se até 21 de junho de 2020. Foram adotadas medidas bastante rígidas de isolamento social até 04 de maio, quando se iniciou um plano gradual de medidas de transição àquilo que o próprio Governo denominou de nova normalidade, a qual se pretende alcançar ao final de junho (GOBIERNO DE ESPAÑA, 2020a).

A adoção das rígidas medidas necessárias à contenção da pandemia acarretou inevitáveis impactos na estrutura de produção, circulação e distribuição de riquezas. Empresas reduziram, suspenderam ou mesmo interromperam suas atividades, ocorrendo o mesmo sobre os rendimentos dos empregados. A circulação de pessoas e recursos, reduzidos ao necessário para os serviços essenciais, inviabilizou grande parte das atividades de trabalhadores autônomos e informais. Ainda que, segundo dados oficiais, o mês de maio de 2020 tenha registrado uma leve recuperação do número de afiliados à seguridade social, indicador este utilizado para mensurar a da taxa de desemprego, entre 12 de março e o final de referido mês foi computado um saldo de mais de 760 mil empregos destruídos (MTMSS, 2020). Para que se tenha melhor percepção das consequências da pandemia sobre o já precário mundo laboral, importante mencionar que, entre as medidas extraordinárias para enfrentar o impacto econômico e social da COVID19, figura a possibilidade de realização de Expedientes de Regulação Temporal de Emprego (ERTEs), ou seja, a suspensão temporária de contratos de trabalho e a

\footnotetext{
${ }^{3}$ Todas as referências a textos normativos e jurisprudenciais utilizados neste trabalho observam tradução livre do idioma espanhol, sem grifos no original.
} 
redução temporária da jornada de trabalho, nos termos do Capítulo III do Real Decreto-Lei 8/2020, de 17 de março. Assim, ao lado de todos aqueles que perderam emprego no período de crise, somem-se quase 3 milhões de trabalhadores cuja relação empregatícia, ao final de maio, encontrava-se suspensa parcial ou totalmente por ERTEs (MTMSS, 2020).

\section{A (IN)SEgURANÇA DE RENDA NA ESTRUTURA DE PROTEÇÃO SOCIAL ANTERIOR À PANDEMIA}

Àqueles que não possuam alguma riqueza acumulada e precisem vender a sua mão-de-obra a terceiros, o artigo 35 da CE/78 prevê o direito à remuneração suficiente para satisfazer suas necessidades pessoais e familiares. Na verdade, o referido dispositivo vai um pouco além, afirmando haver não apenas um direito ao trabalho, mas também o dever de trabalhar. Embora a $\mathrm{CE} / 78$ não crie um verdadeiro dever de trabalhar, haja vista a total falta de transcendência prática de tal previsão, e tampouco um direito subjetivo a um posto de trabalho, como se verá mais adiante, ela destaca o papel do emprego na estrutura de inserção e proteção social a ser desenvolvida pelo Poder Legislativo. Neste sentido, o artigo 40.1, ao tratar de redistribuição de renda e pleno emprego, dispõe que:

Os poderes públicos promoverão as condições favoráveis para o progresso social e econômico e para uma distribuição da renda regional e pessoal mais equitativa, no marco de uma política de estabilidade econômica. De maneira especial realizarão uma política orientada ao pleno emprego.

Entretanto, como já exposto na introdução, há muito o desemprego é algo estrutural na sociedade espanhola, de modo que o trabalho não logra a inserção social de parte significativa da população. Considerando este elemento, a CE/78 trata de prever as bases de uma rede de proteção social para aqueles que, por motivos temporários ou permanentes, encontrem-se fora do mundo do trabalho remunerado. $\mathrm{O}$ artigo 41 endereça a preocupação com a proteção social, ao dispor que:

Os poderes públicos manterão um regime público de Seguridade Social para todos os cidadãos, que garanta a assistência e prestações sociais suficientes ante situações de necessidade, especialmente em caso de desemprego. A assistência e prestações complementares serão livres.

Note-se que, embora a seguridade social seja destinada a todos os cidadãos, a especial preocupação com as situações de desemprego reitera o caráter do trabalho remunerado como eixo central de inserção social, o que vai inspirar uma legislação 
infraconstitucional com prestações contributivas, em regra vinculadas aos aportes do trabalhador ao longo do exercício profissional, e não contributivas, estas sim destinadas a todos os indivíduos independentemente de sua relação com o mundo laboral.

Uma análise meramente literal e topográfica pode levar a crer que os citados artigos 40 e 41 tratam de direitos fundamentais, por fazerem parte do Capítulo Terceiro (artigos 39 a 52), dedicado aos "Princípios reitores da política social e econômica", do Título I, denominado "Dos direitos e deveres fundamentais". Entretanto, a concepção constitucionalmente adequada do tema sequer permite afirmar que há um direito constitucional à redistribuição de renda, ao pleno emprego, à assistência social ou mesmo à seguridade social, salvo o caso dos reclusos do sistema prisional, aos quais é assegurado o direito fundamental ao trabalho remunerado e aos benefícios correspondentes da seguridade social (artigo 25.2).

Isto porque o artigo 53.3, ao se referir ao Capítulo Terceiro do Título I, é claro ao estabelecer que, embora o reconhecimento, respeito e proteção dos princípios previstos em tal capítulo devam informar a legislação positiva, a atividade judicial e a atuação dos poderes públicos, eles somente poderão ser alegados ante a jurisdição ordinária, ou seja, somente serão verdadeiros direitos, com seus elementos definidos, de acordo com o que disponham as leis que os desenvolvam ao escolher a opção política mais adequada para dar concreção ao que fora constitucionalmente previsto. Conforme afirma BASTIDA FREIJEDO (2007, p. 138), seria um contrassenso se a CE/78 proclamasse como direito fundamental um dos princípios previstos no Capítulo Terceiro e, ao mesmo tempo, deixasse a definição de seu objeto, conteúdo e limites à disponibilidade do legislador.

Em outros termos, embora as previsões constitucionais sobre os direitos sociais contidas no Capítulo Terceiro sejam vinculantes aos poderes públicos, pois determinam os fins a serem perseguidos, não geram direitos subjetivos, pois deixam à legislação infraconstitucional a definição dos meios a serem utilizados. Desta forma, desde uma perspectiva jurídico-positiva, somente os dispositivos contidos nos Capítulos Primeiro (artigos 11 a 13) e Segundo (artigos 14 a 38) do Título I da CE/78 possuem o status de direitos fundamentais, estando, assim, fora da disponibilidade do Poder Legislativo, e fazendo parte do campo de disposição imediata dos seus titulares, com conteúdo e objeto determinados. Por consequência, salvo casos excepcionais como o direito à educação básica (artigo 27.4), e os direitos à liberdade sindical (artigo 28.1) e de greve (artigo 28.2), os chamados direitos sociais não possuem o caráter de direito fundamental na estrutura constitucional espanhola, não podendo ser demandados judicialmente como direitos subjetivos diretamente fundados na $\mathrm{CE} / 78$. Uma vez que tais dispositivos demandam interposição legislativa para que constituam direitos subjetivos, resta saber a quem cabe a competência para legislar sobre os temas de proteção social em Espanha. 
É importante destacar que Espanha não é uma federação de Estados, e tampouco um Estado unitário completamente centralizado. Trata-se de um Estado unitário autonômico (artigo $2^{\underline{o}}$ ), ou seja, um Estado que, nos termos do artigo 137 da CE/78, organiza-se territorialmente em comunidades com autonomia para gerir seus respectivos interesses, sejam elas regionais, as Comunidades Autônomas propriamente ditas (CCAA), ou locais, os municípios e as províncias. Considerando-se que as entidades locais não possuem competência legislativa, interessa analisar a competência do Estado e das CCAA sobre a estrutura de proteção social.

Nos termos do artigo 149.1.17, o Estado possui competência exclusiva sobre legislação básica e regime econômico da Seguridade Social, sem prejuízo da execução de seus serviços pelas CCAA. Por sua vez, o artigo 148.1.20 permite que as CCAA assumam competência em matérias de assistência social. De fato, ao criar seus Estatutos de Autonomia, exercendo a prerrogativa do artigo 147.2.d, todas as CCAA dispuseram acerca de competências exclusivas em matéria de serviços sociais, sob uma fórmula genérica e compreensiva que abarca temas de assistência social (MERCADER UGUINA, 2018, seç. I).

Então, para compreender como se dá esta divisão de competência, resta saber qual é, no âmbito da estrutura constitucional espanhola, a diferença e a relação entre assistência social e seguridade social. O primeiro ponto a destacar-se é que, no texto da CE/78, a única referência expressa a "assistência social" se encontra na norma de competência do artigo 148.1.20, o que não impede notar que ela estaria implícita a outras previsões, como o princípio da distribuição de renda do artigo 40, mas também não significa que ela necessariamente se confunda com a "assistência" mencionada no artigo 41, ao tratar da seguridade social. Em outros termos, a noção de assistência social não é precisa nos enunciados constitucionais, carecendo de labor interpretativo, pelo que se passa à análise das Sentenças do Tribunal Constitucional de Espanha (STC) sobre o tema, em especial seus Fundamentos Jurídicos (FJ).

Embora o artigo 41 não crie um direito subjetivo, ele estabelece uma garantia institucional à Seguridade Social. É neste sentido a interpretação do TC, segundo o qual a Seguridade Social é uma função do Estado, cabendo à legislação configurar a estrutura de proteção a situações ou estados de necessidade, o que pode ser feito tanto por meio de medidas contributivas, conteúdo tradicional do sistema, quanto de medidas não contributivas, de conteúdo assistencial (STC 76/1986, FJ7; STC 65/1987, FJ7; STC 37/1994, FJ3; STC 239/2002, FJ5). Ao contrário da Seguridade Social, que se configura como um sistema integrado, público e imperativo, as prestações das CCAA no âmbito da assistência social não exigem a sua integração a um sistema permanente no tempo e no espaço, sendo permitida inclusive àquelas proceder a uma diferente configuração em seus respectivos territórios (STC 239/2002, FJ8). Embora o artigo 41 seja neutro no que se refere à distribuição competências, ele impõe a todos os poderes públicos, cada qual em suas respectivas 
atribuições, um chamamento para paliar as situações de necessidade (STC 206/1997, FJ 5; STC 239/2002, FJ3).

Assim, por meio de uma interpretação do artigo 41 no marco do bloco de constitucionalidade ${ }^{4}$, o TC considerou pertinente inferir que há uma assistência social "interna" ao sistema de Seguridade Social, sob a competência estatal do artigo 149.1.17, e outra "externa" a tal estrutura, sob a competência exclusiva das CCAA nos termos do artigo 148.1.20 (STC 239/2002, FJ5). Entretanto, uma competência exclusiva não significa a existência de uma competência excludente da atuação dos demais entes no campo social (STC 146/1986, FJ5), de modo que há uma confluência de competências, uma faixa comum, na qual tanto o Estado quanto as CCAA podem atuar. Isto porque, em havendo pessoas que não tenham suas necessidades mínimas cobertas mesmo após receber as prestações não contributivas do sistema de Seguridade Social, o paradigma constitucional do Estado Social de Direito exige que elas possam ter acesso a benefícios de diferente natureza. Esta zona de assistência interna ao sistema estatal, quando precisa de complementação de outras fontes para assegurar o princípio da suficiência do artigo 41, coincide com a competência das CCAA (STC 239/2002, FJ7).

Assim, em respeito à competência estatal estabelecida pelo artigo 149.1.17, a atuação das CCAA deve observar dois requisitos: a) situação de real necessidade na população beneficiária das ajudas assistenciais da Seguridade Social; e b) não interferência no regime jurídico básico ou no regime econômico da Seguridade Social (STC 239/2002, FJ7). A partir desta compreensão, não se pode admitir que a tendência de universalização das medidas estatais de proteção social, em linha com o objetivo previsto no artigo 41 da CE/78, implique na redução de âmbitos de proteção social externos ao sistema de Seguridade Social. Em suma, a ampliação da atuação do Estado não pode significar o esvaziamento das competências autonômicas, pois o alargamento do campo de contingências protegidas pela Seguridade Social não exclui, por si só, a existência de necessidades específicas de diversos coletivos, que precisem ser atendidos por apoios complementares prestados pelas CCAA (STC 239/2002, FJ6).

Esta breve digressão acerca do sistema constitucional de competências não é algo etéreo ou desprovido de transcendência prática. Como se verá nos parágrafos seguintes, a divisão competências não só foi determinante para a configuração de uma estrutura de proteção bastante fragmentada e heterogênea ao longo das últimas décadas, com todas as consequências práticas que isto pode trazer para a

\footnotetext{
${ }^{4}$ A ideia de bloco de constitucionalidade deve aqui ser entendida nos termos do artigo 28.1 da Lei Orgânica 2/1979 (Lei Orgânica do Tribunal Constitucional - LOTC), segundo o qual "[p]ara apreciar a conformidade ou não conformidade com a Constituição de uma lei, disposição ou ato com força de Lei do Estado ou das Comunidades Autónomas, o Tribunal considerará, além dos preceitos constitucionais, as Leis que, no marco constitucional, tenham sido promulgadas para delimitar os poderes do Estado e das diversas Comunidades Autónomas ou para regular ou harmonizar o exercício das competências destas.".
} 
sua eficácia e para o atendimento a outros preceitos constitucionais, como também volta à baila com a exposição das fraturas sociais em tempos de crise.

Aclaradas qual a natureza constitucional da proteção a pessoas em situação de necessidade, bem como a competência para legislar sobre o tema, resta fazer algumas considerações sobre aquilo que já fora legislado especificamente sobre proteção das pessoas e grupos em situação de vulnerabilidade causada pela pobreza.

Reiterando a preocupação com emprego, o Estado, por meio do Real Decreto 1369/2006, instituiu o programa de renda ativa de inserção para desempregados. Tal medida teve cobertura extremamente restritiva, por diversos motivos, como direcionar-se exclusivamente a trabalhadores entre 45 e 65 anos (artigo 2.1.a), além de ter duração limitada a 11 meses (artigo 5.1).

Considerando-se que os tratados internacionais validamente celebrados e publicados fazem parte do ordenamento jurídico interno (artigo 96.1, CE/78), fazse relevante destacar que Espanha assinou e ratificou a versão original da Carta Social Europeia (CSE) de 1966. Conforme o artigo 13.1 da Parte II de referido tratado, os Estados Partes comprometem-se a:

assegurar que qualquer pessoa que não disponha de recursos suficientes e que não esteja em condições de os angariar pelos seus próprios meios ou de os receber de outra fonte, designadamente por prestações resultantes de um regime de segurança social, possa obter uma assistência apropriada e, em caso de doença, os cuidados necessários ao seu estado.

No direito interno, a partir do previsto no artigo 148.1.20 da CE/78, as CCAA assumiram competências de assistência social e legislaram, cada qual a seu modo e em momentos distintos, sobre políticas de garantia de uma renda mínima aos cidadãos residentes em seus territórios. Uma vez que Espanha possui dezessete CCAA e duas cidades autônomas, o resultado é a existência de nada menos que dezenove sistemas autonómicos de renda mínima em Espanha (MSCBS, 2018, p. 15-27). Embora sob distintas nomenclaturas, tais políticas podem ser consideradas como aquilo que genericamente se denominam políticas de Renda Mínima Garantida (RMG) ou Renda Mínima de Inserção (RMI), uma vez que são direcionadas aos mais pobres, para garanti-los um mínimo de ingressos, aos quais impõem algumas condições, em regra vinculadas à busca da inserção social por meio do trabalho.

Ou seja, na ausência de uma ferramenta dentro da estrutura de Seguridade Social do Estado desenhada para paliar a pobreza estrutural, cada CCAA elaborou sua própria política de assistência destinada a aliviar a necessidade de renda dos residentes em seus territórios. Conforme já apontado pelo TC, as políticas de RMI desenvolvidas pelas CCAA são ajudas de assistência social, externas ao sistema de 
Seguridade Social, podendo ser recebidas inclusive pelos beneficiários de pensões próprias deste sistema (STC 239/2002, FJ6).

Esta resposta fragmentada à questão resultou em programas bastante heterogêneos, o que se evidencia na própria natureza do benefício prestado, ora como direito subjetivo, ora como subvenção condicionada à disponibilidade orçamentária, assim como nos critérios de elegibilidade, na definição dos módulos familiares, nas condições de permanência, no valor e na duração da prestação. Diversos estudos apontam que esta solução, por ser descentralizada, desconexa e desigual, envolvendo normas e aplicações práticas bastante distintas, resulta em cobertura de caráter assistencial insuficiente na luta contra a pobreza e a exclusão social $^{5}$, sendo que a ausência de uma atuação estatal sistemática gera uma situação que pode ser contrastada com o mandamento constitucional do artigo 139, que garante a todos os espanhóis, em qualquer parte do território do Estado, os mesmos direitos e obrigações.

Por mais que o presente estudo se dedique a uma análise normativa, pouco se pode falar de suficiência de uma estrutura de proteção social sem que sejam analisados alguns dados da realidade social à qual as normas se aplicam. Pois bem, em 2018 as políticas de RMI alcançavam menos de 1,5\% da população espanhola (MSCBS, 2018, p. 92). Em uma sociedade que, conforme apontado na introdução, $21,50 \%$ das pessoas estavam em situação de risco de pobreza, a conjugação de tais dados denota uma estrutura que atribui pouca concreção ao princípio de suficiência do artigo 41 da CE/78.

Analisando-se os dados das dezenove distintas políticas autonómicas de RMI, em 2018, nota-se que o valor médio da quantia mínima efetivamente paga à unidade familiar unipessoal era de 463,05 €, variando entre os módulos básicos de 300,00 €, em Ceuta, a 644,49 €, no País Vasco (MSCBS, 2018, p. 99-100). Considerando-se que, em regra, tais benefícios são pagos de maneira complementar aos demais ingressos recebidos pelo beneficiário até atingir o valor do módulo no qual a unidade familiar se encaixa, tem-se que em nenhum dos casos o benefício autonômico de RMI era matematicamente suficiente para romper o umbral de $740 €$, a partir do qual o indivíduo estaria fora do risco de pobreza. Ou seja, além de os benefícios de RMI não alcançarem todas as pessoas que deles necessitam, quando chegam não o fazem em um nível suficiente para tirá-las do risco de pobreza.

No que toca à CSE, o Comitê Europeu dos Direitos Sociais (CEDS), órgão máximo encarregado da interpretação, defesa e controle das normas e práticas dos Estados Partes do tratado, já se posicionou sobre o tema. De acordo com as suas Conclusões XXI-2(2017), Espanha não está em conformidade com o artigo 13.1 da Parte II da CSE pelas seguintes características de suas políticas de RMI: a) os critérios de elegibilidade estão sujeitos a um período mínimo de residência na

${ }^{5}$ Cf. AIREF, 2019, p. 15; BERGANTIÑOS; FONT QUILES; BACIGALUPE, 2017, p. 414; ARGÜELES BLANCO, 2017, p. 135; GOBIERNO DEL PRINCIPADO DE ASTURIAS, 2017a, p. 28, 2017b, p. 18. 
maioria das CCAA; b) os critérios de elegibilidade estão sujeitos à idade (mínimo 25 anos); c) o período de duração da renda mínima não se relaciona com a persistência da necessidade, mas sim com prazos que operam de maneira independente a ela; e d) o nível de assistência social paga a uma pessoa não é adequado, pois está debaixo do limiar de pobreza, exceto na Comunidade Autónoma do País Vasco (COUNCIL OF EUROPE, 2017, p. 28-31).

Já durante da pandemia, em 20 de maio de 2020, o Conselho da UE apresentou suas recomendações ao Programa Nacional de Reformas de 2020 de Espanha, dentre as quais, reiterando algo já apontado desde 2014, consta a melhoria da cobertura e adequação dos esquemas de renda mínima (COUNCIL OF THE EUROPEAN UNION, 2020).

\section{A CRIAÇÃo do INGRESSO MíNIMO VitAL}

Após aprovação, em 29 de maio, pelo Conselho de Ministros, órgão colegiado do Governo, foi publicado no Boletim Oficial do Estado (BOE) de 1 de junho de 2020 o Real Decreto-lei 20/2020, que estabelece o Ingresso Mínimo Vital (IMV). Embora tal política fosse parte do plano de governo como uma resposta estrutural ao problema da pobreza e da má distribuição de renda, a emergência sanitária ocasionada pela COVID-19 serviu de argumento para acelerar sua implementação. Não sem críticas da oposição, isto foi determinante para a justificativa da forma normativa adotada pelo Governo, o Real Decreto-lei, que, nos termos do artigo 86 da CE/78, exige como pressuposto habilitante a extraordinária e urgente necessidade, permitindo a sua vigência provisória antes da deliberação do Congresso de Deputados.

Para melhor compreensão didática, e sem a pretensão de exaurimento dos tópicos tratados no Real Decreto-lei 20/2020, os parágrafos que seguem se dedicarão a esclarecer "o que é?", "a quem se destina?", "sob quais condições?" e "por quem é devido?" o IMV.

\subsection{A prestação econômica}

Já no artigo 1, o IMV se apresenta como uma medida dirigida a prevenir o risco de pobreza e de exclusão social de pessoas em situação de vulnerabilidade por não disporem de recursos materiais para atender suas necessidades básicas. Como se verá adiante, ao se realizar a análise dos valores assegurados, este primeiro dispositivo é tão animador quanto ilusório.

O IMV se configura como um direito subjetivo a uma prestação mensal de natureza econômica para garantir um nível mínimo de renda àqueles que, em situação de vulnerabilidade econômica, cumpram com os requisitos do Real Decreto-lei (artigos 2.1 e 9). O valor base do IMV é a quantia de renda garantida a uma pessoa beneficiária individual (lar unipessoal), que equivale ao valor das pensões não contributivas da Seguridade Social, determinado anualmente pela lei orçamentária do Estado. Para o exercício de 2020, tal valor é de 5.538,00€ anuais, o 
que equivale a 461,50 $€$ mensais (artigo 10.2.a c/c 10.5). Caso se trate de uma unidade de conivência (UC), a renda garantida equivale ao valor base do lar unipessoal incrementado de $30 \%$ por membro adicional a partir do segundo, até um máximo de $220 \%$. Ou seja, a partir de 5 membros o valor garantido à UC é o mesmo, qualquer que seja o seu tamanho (artigo 10.2.b). A especial preocupação com as famílias monoparentais está expressa na atribuição de um adicional de $22 \%$ do valor base a tal formação familiar (artigo 10.2.c). Frise-se que o adicional é devido pela condição de monoparentalidade, não pelo número de menores sob responsabilidade da pessoa beneficiária. Assim, por exemplo, uma mãe que tenha sob sua responsabilidade três filhos será titular de um benefício equivalente a $212 \%$ o valor base, ou seja, $100 \%$ da titular acrescidos de três vezes o adicional de $30 \%$ devido por membro adicional, para o qual é indiferente a condição de adulto ou menor, e um adicional de $22 \%$ de monoparentalidade.

Destaque-se que o IMV se destina a garantir um nível mínimo de renda, o que significa que, após verificado o nível de renda do lar unipessoal ou da UC, conforme o caso, o Estado realizará o pagamento do valor complementar da diferença necessária para alcançar o nível assegurado, de modo que o valor recebido será igual ao total da renda garantida apenas naqueles casos em que a renda prévia da pessoa ou UC beneficiária seja igual a zero (artigos 3.a c/c10.1).

As solicitações poderão ser apresentadas a partir de 15 de junho de 2020 (Disposição transitória segunda) e titular terá direito a receber o IMV a partir do primeiro dia do mês seguinte ao da solicitação, o que se realizará por meio de transferência à sua conta bancária (artigo 11). Tal direito se manterá enquanto os elementos que motivaram sua concessão persistam, desde que cumpridas as obrigações e requisitos legais (artigo 12). Ou seja, não se trata de uma prestação temporária, com duração pré-determinada, mas sim destinada a existir enquanto se verifique a situação de necessidade. Cabe ao Instituto Nacional de Seguridade Social (INSS) avaliar as solicitações de IMV em até 3 meses a partir do seu recebimento. Caso tal prazo transcorra sem nenhuma resolução expressa, entendese indeferido o pedido por silêncio negativo (artigo 25.2). Considerando-se que se trata de prestação destinada a atender pessoas em situação de extrema vulnerabilidade, não soa razoável que o possível beneficiário, após juntar toda a documentação necessária e suportar 3 meses de necessidades materiais durante a omissão do Estado, tenha seu pedido indeferido em virtude da desídia deste. $\mathrm{O}$ silêncio positivo seguramente seria uma alternativa mais coerente com os princípios constitucionais que orientam o sistema de Seguridade Social.

\subsection{O âmbito subjetivo de aplicação}

No que se refere à segunda das questões, a lógica de estruturação do IMV mostra que ele não se trata de uma prestação destinada ao indivíduo em si mesmo, mas sim na condição de integrante de um lar. Este pode ter um membro (lar unipessoal) ou mais (UC). Isto justifica a diferenciação entre pessoas beneficiárias 
(artigo 4) e titulares (artigo 5), posto que o titular será o único beneficiário somente quando more sozinho. Quanto à sua caracterização, a UC se constitui, em regra, de todas as pessoas que residam no mesmo domicílio há pelo menos 1 ano contínuo, unidas entre si por vínculo matrimonial ou como união de fato, ou por vínculo sanguíneo de até segundo grau, afinidade, adoção ou acolhimento familiar permanente (artigos 6.1 e 7.2.3).

Poderão ser beneficiárias do IMV, além das pessoas integrantes de uma UC (artigo 4.1.a) e as pessoas entre 23 e 65 anos que morem sozinhas (lar unipessoal). As pessoas entre 23 e 65 anos, que residam com outras sem que mantenham entre si vínculo caracterizador de uma UC, serão a esta equiparadas em determinadas circunstâncias (artigos 4.1.c e 6.2.c). Para que se possa caracterizar um lar unipessoal, a pessoa não deve ter com outra vínculo matrimonial ou união de fato, salvo se estiver em tramites de divórcio ou separação, e não fazer parte de uma UC, exceto em situações de mulheres vítimas de violência de gênero ou vítimas de tráfico humano e exploração sexual (artigo 6.1). Para caracterização do lar unipessoal, exige-se também que a pessoa tenha morado de forma independente por ao menos três anos antes de solicitar o IMV (artigo 7.2).

Posto que a escolha de critério de diferenciação com base na idade, característica que foge ao controle dos indivíduos, converte-se em elemento suspeito se não devidamente justificada, embora a exclusão dos maiores de 65 anos seja justificável pelo fato de o sistema de Seguridade Social contar com outras medidas especificamente direcionadas a eles, a exclusão dos menores de 23 anos merece uma análise um pouco mais detida à luz da CE/78.

Nos termos do artigo 315 do Código Civil Espanhol, a maioridade começa aos 18 anos completos. Sem dedicar nenhuma palavra das quase 12 laudas de suas Disposições Gerais para justificar tal opção legislativa, o Real Decreto-lei deixa de fora da cobertura do IMV toda uma faixa composta por pessoas maiores, entre 18 e 23 anos de idade, que não se encontrem integradas a nenhuma UC. Ante a ausência de motivação, resta difícil entender se tal restrição se deu pelo fato de o Governo acreditar que não há pobres na faixa etária excluída, que os jovens não devem sair da casa de sua família antes dos 23 anos de idade ou mesmo por ignorar a situação de jovens tutelados que se veem obrigados a deixar os Centros de Menores ao atingir a maioridade sem ter uma família à qual se integrar. Seja por ignorar os dados, por querer impor alguma forma de controle de formação familiar ou mesmo por descaso para com aqueles jovens que são totalmente impossibilidades de se integrarem a uma UC, além dos problemas específicos que cada caso envolve, há por trás deste critério legal uma cláusula suspeita que esbarra no direito fundamental à igualdade perante a lei (artigo 14 da CE/78). Conforme já manifestou o TC, ao interpretar a proibição contida no artigo 14 da CE/78, a idade não pode ser razão para qualquer discriminação. Assim, tal elemento pessoal somente pode ser levado em consideração pela norma nos casos em que ele seja relevante para a finalidade legítima e não discriminatória por ela perseguida (STC 69/1991). 
Não é demais reiterar que a exclusão dos jovens das políticas de RMI autonômicas já foi apontada pelo CEDS como um fator de não observância do artigo 13.1 da Parte II da CSE por parte de Espanha, a partir da constatação de que, as políticas de garantia de renda das CCAA deixavam de fora os menores de 25 anos. Embora não exista hierarquia jurídica entre as normas da CSE, adotada pelo Conselho da Europa (Council of Europe), e as extraídas de outros tratados internacionais, como os que formam o direito comunitário da $\mathrm{UE}^{6}$, o papel secundário atribuído pelo Estado espanhol àquelas em relação a estas salta aos olhos ao se analisar as Disposições Gerais do Real Decreto-lei 20/2020, que nenhuma referência faz às normas da CSE ou às vinculantes conclusões do CEDS enquanto busca motivação da norma em recomendações de órgãos comunitários.

Assim, desde uma perspectiva constitucional e de normas de tratados integrados ao ordenamento interno, estaria bem que o legislador ao menos se preocupasse em tentar demonstrar a legitimidade e o caráter não discriminatório de sua opção ao afastar do IMV as pessoas entre 18 e 23 anos que não estão integradas a uma UC.

São estabelecidos quatro requisitos de acesso à condição de pessoa beneficiária do IMV. O primeiro é a exigência de residência legal e efetiva em Espanha de forma contínua e ininterrupta de pelo menos um ano anterior à data de apresentação da solicitação, excetuadas situações de incorporação de menores, vítimas de tráfico humano e exploração sexual e mulheres vítimas de violência de gênero. (artigo 7.1.a). Note-se que o critério está no período de residência, e não na nacionalidade da pessoa, de modo que também as pessoas estrangeiras poderão ser beneficiárias do IMV.

Como segundo critério, exige-se que as pessoas beneficiárias estejam em situação de vulnerabilidade econômica por carência de rendas ou patrimônio suficientes, para isto sendo considerada a capacidade econômica do indivíduo, caso more sozinho, ou de todos os membros, caso se trate de uma UC (artigos 7.1.b c/c 8.1). Caracteriza-se a situação de vulnerabilidade econômica quando a média mensal do conjunto de ingressos e rendimentos anuais da pessoa beneficiária individual ou o conjunto de membros da $\mathrm{UC}$, relativos ao exercício anterior, seja pelo menos $10 €$ inferior à quantia da renda mensal garantida de acordo com a modalidade (beneficiária individual ou UC) e o número de membros da UC (artigo 8.2). Para os casos em que a situação de vulnerabilidade tenha se caracterizado durante o ano de 2020, há a previsão de um regime excepcional que permite a solicitação do IMV com base nos rendimentos proporcionais do ano em curso (Disposição transitória terceira).

O Real Decreto-lei abre espaço para que futuro regulamento estabeleça as situações em que a superação do limite de renda garantida por meio dos ingressos provenientes do trabalho ou de atividade econômica por conta própria da pessoa

' Para uma análise mais aprofundada, veja-se JIMENA QUESADA, 2017; SALCEDO BELTRÁN, 2014. 
beneficiária seja compatível com o recebimento do IMV (artigo 8.4). Tal medida busca evitar a chamada armadilha da pobreza, situação na qual a pessoa beneficiária não se vê incentivada a buscar outras fontes de renda por receio de deixar de receber a prestação pública.

Além do limite de rendas, há um limite de patrimônio. As pessoas beneficiárias individuais do IMV não devem ter um patrimônio avaliado em mais do que três vezes o valor base da renda garantida ao lar unipessoal. No caso de UC, há um escalonamento de limite de patrimônio que, em suma, a partir do limite de patrimônio do lar individual, fixa em 1,4 vezes tal valor para a UC de duas pessoas, 1,8 vezes para a UC de três pessoas, 2,2 vezes para a UC de quatro pessoas e 2,6 para a UC de cinco pessoas (artigo 8.3 c/c Anexo II). Em qualquer dos casos, não integra a avaliação do patrimônio o valor da moradia habitual (artigo 18.4). Ademais, independente da valoração do patrimônio, não farão jus ao IMV a pessoa, ou a UC que ela integre, que seja administradora de direito de uma sociedade mercantil (artigo 8.3).

O terceiro critério impõe à pessoa que, antes de solicitar o IMV, tenha solicitado todas as pensões e prestações a que eventualmente possa ter direito, excetuadas as prestações de políticas de RMI da CCAA (artigo 7.1.c). Isto denota a natureza do IMV como penúltima rede de proteção, subsidiária a todas as demais, exceto às da assistência autonômica.

O quarto critério exige que as pessoas que não estejam trabalhando, maiores ou menores emancipados, figurem como demandantes de emprego (7.1.d). Ou seja, salvo as hipóteses previstas em regulamento, o IMV não se destina àquelas pessoas que não trabalhem ou não estejam buscando emprego. É uma prestação devida não em função do sujeito "pessoa humana", mas sim do predicado "trabalhadora", potencial ou atual.

Agora que já se sabe a quem se destina o IMV e qual o valor base para uma pessoa sozinha, considerando que a média do valor por pessoa se reduz consideravelmente à medida em que aumenta o número de membros da UC, fazse possível uma primeira consideração a respeito da eficácia do IMV para atingir o objetivo que o próprio artigo 1 do Real Decreto-lei 20/2020 se propõe, qual seja, prevenir o risco de pobreza e exclusão social.

Uma conta simples mostra que a quantia base que o IMV garantirá mensalmente a um lar individual (461,50 €) não chega a 63\% daquilo que, em 2018, era considerado como umbral do risco de pobreza em Espanha $(740,00 €)$. Ou seja, o IMV não se trata sequer de uma medida direcionada aos pobres, mas sim aos paupérrimos, deixando uma considerável faixa de população vulnerável descoberta. Isto afasta, por exemplo, qualquer afirmação de que o IMV se destina a cobrir isoladamente todo o mínimo existencial (Existenzminimum), tal como conhecido nas jurisprudências alemã e brasileira, haja vista este conceito possuir conteúdo muito mais amplo que a mera satisfação de necessidades fisiológicas, 
dirigindo-se à cobertura da inserção social e da participação na vida política e cultural 7 .

Não se pode desprezar o potencial do IMV para paliar a pobreza extrema e redistribuir a renda da sociedade espanhola, tal como o objetivo expresso de forma mais realista no item V das Considerações Gerais. Conforme cálculos do Governo, o IMV deve chegar a 850 mil lares, em que vivem 2,3 milhões de pessoas, das quais $30 \%$ são menores, erradicando-se a pobreza extrema, que atinge os 600 mil lares e 1,6 milhões de pessoas mais pobres de Espanha (GOBIERNO DE ESPAÑA, 2020b, p. 3, 2020c, p. 11). Entretanto, não é razoável afirmar que uma medida prevista para alcançar menos de $5 \%$ da população, mesmo ignorando toda a possibilidade da falta de adesão e considerando que todas aquelas pessoas que cumpram os requisitos venham de fato a receber a prestação ${ }^{8}$, está direcionada a prevenir o risco de pobreza, que atinge nada menos que $21,5 \%$ dos residentes no país.

\subsection{As condições impostas}

Uma vez tecidas as considerações gerais sobre o que é a prestação devida pelo IMV, e a quem é devida, importante esclarecer quais as condições que a norma impõe para que a pessoa, uma vez inserida no rol de beneficiários, preserve tal condição. Embora o Real Decreto-lei dedique todo um capítulo (VII) para tratar das obrigações e outro (VIII) para cuidar das infrações e sanções, denotando sua grande preocupação com o controle dos beneficiários, a presente análise se incidirá apenas sobre alguns pontos ilustrativos.

É obrigação de todas as pessoas beneficiárias comunicar à entidade gestora competente, no prazo de 30 dias corridos, quaisquer alterações nas circunstâncias relativas aos requisitos e obrigações relacionadas ao IMV (artigos 12.1 e 33.1.b), sendo que tais alterações poderão significar o aumento ou a diminuição do valor recebido que, em qualquer caso, será revisado no primeiro dia de cada ano a partir da variação de ingressos anuais computados no exercício anterior (artigo 13). Caso o titular do IMV, por qualquer motivo, não cumpra alguma de suas obrigações, cabe aos demais membros da UC fazê-lo (artigo 33.2.d).

Serão motivos de suspensão do direito ao IMV, dentre outros que venham a ser estabelecidos no regulamento, a perda temporal de algum dos seus requisitos, o descumprimento temporário das obrigações impostas a qualquer dos beneficiários e o descumprimento de qualquer das condições associadas à compatibilidade do IMV com rendas oriundas do trabalho ou de atividade econômica (artigo 14.1). Desaparecidas as causas que deram origem à suspensão, será retomado de ofício o pagamento (artigo 14.3). Se a suspensão durar um ano, será o direito extinto (artigo 15.1.f).

\footnotetext{
7 Para melhor compreensão da abrangência do mínimo existencial, cf. ROCHA, 2017; SARLET; ZOCKUN, 2016.

${ }^{8}$ Sobre os impactos da não adesão dos possíveis beneficiários às políticas de RMI das CCAA, cf. FUENMAYOR FERNÁNDEZ; GRANELL PÉREZ, 2013.
} 
A condição de demandante de emprego se mantém como obrigação das pessoas beneficiárias, quer em lar individual ou como membro de uma UC, durante a percepção da prestação econômica (artigos 33.1.f e 33.2.e), devendo ainda participar das estratégias de inclusão que promova o Ministério de Inclusão, Seguridade Social e Migrações (artigos 33.1.h e 33.2.g). Por trás desta obrigação, assim como da acima referida preocupação com a armadilha da pobreza, está a ideia da inserção por meio do trabalho, a chamada ativação social, como se não fosse ativo aquele que não vende sua mão de obra a terceiros, ainda que exerça labores de grande relevância para a sociedade, como os serviços de cuidados ou trabalhos voluntários.

Conforme consta no item III das Disposições Gerais, o IMV não se trata de uma prestação econômica com fim em si mesma, mas sim uma ferramenta para facilitar a transição dos indivíduos à inclusão social de incorporação ao mercado de trabalho, acesso a oportunidades educativas ou solução de uma condição sanitária. O artigo 8.4 já se inicia destacando a preocupação com que o recebimento do IMV não desestimule a participação no mercado laboral. Para incentivar a colaboração das empresas neste processo, a Disposição Adicional Primeira prevê a criação do Selo de Inclusão Social, destinado ao reconhecimento dos empregadores de beneficiários do IMV. Mais uma vez, vê-se a estrutura de inserção social girar em torno de um eixo que simplesmente não existe para grande parte da população espanhola, o emprego, como se tivesse um valor em si mesmo e o afastamento do mundo do trabalho fosse uma livre escolha da pessoa, e não o resultado de um problema de desemprego estrutural sem perspectivas de resolução.

Após classificar as infrações como leves, graves e muito graves, o Real Decretolei prevê um sistema escalonado de sanções, a serem impostas por meio de procedimento administrativo (artigo 36), que vai desde a advertência à exclusão do sujeito infrator da possiblidade de ser beneficiário do IMV por um período de dois anos. A responsabilidade das infrações tipificadas não se restringe aos beneficiários da prestação, podendo alcançar a terceiros que tenham cooperado ativa ou omissivamente para seu cometimento, respondendo solidariamente pela devolução dos valores indevidamente recebidos (artigo 34).

Assim, a norma permite ao Estado um amplo controle social sobre o indivíduo, desde a contínua verificação de sua composição familiar até a imposição de condutas relacionadas ao trabalho. Aquelas pessoas que não conseguem se submeter às precárias condições do mercado de trabalho são empurradas à submissão a uma atuação estigmatizante do Estado, perante o qual devem continuamente atestar sua extrema pobreza, aceitando inclusive a imposição de qualquer condição ou obrigação que o Governo venha a determinar por meio de regulamento. Em um ordenamento jurídico que assegura ao indivíduo o livre desenvolvimento da personalidade (artigo 10.1 da CE/78), merece ser questionada a tentativa do Estado impor uma determinada concepção de boa vida por meio do controle social dos necessitados. 


\subsection{Os Poderes Públicos Envolvidos}

O IMV se trata de uma prestação não contributiva prestada pelo Estado, no âmbito da Seguridade Social (artigo 2.2), sendo o orçamento desta a fonte dos recursos para financiamento de sua implementação (artigo 32), estimados em um total de 3 bilhões de Euros por ano (GOBIERNO DE ESPAÑA, 2020b, p. 4). O IMV dá ao sistema de Seguridade Social novo equilíbrio, ao superar um modelo cujo protagonismo até então residia nas prestações contributivas.

Considerando-se o princípio de suficiência do artigo 41 da CE/78, que impõe a todos os poderes públicos a busca da satisfação das necessidades materiais básicas de todas as pessoas, o IMV se apresenta como uma base a partir da qual podem ser feitas complementações assistenciais pelas CCAA, de acordo com a realidade de cada uma. Justamente por isto, não se computam os valores recebidos dos programas autonômicos de RMI na análise de rendas e patrimônio das pessoas beneficiárias para fins de concessão do IMV (artigos 8.2 c/c 18.1. e.1ํ). Ou seja, os valores de rendas mínimas pagos pelas CCAA seguem com seu caráter subsidiário em relação a todos os benefícios eventualmente pagos pelo Estado, cabendo agora às CCAA ajustar o direcionamento de suas políticas para que possam atuar como proteção àqueles não contemplados pelo IMV, ou mesmo complementar aos valores da política do Estado, aumentando o nível de proteção para os residentes em seus respectivos territórios.

Além da competência específica para concretar a garantia institucional de um sistema de Seguridade Social (artigo 149.1.17), o Estado busca justificar, por meio da Disposição Final Nona, sua competência por considerar estar atuando na regulação de condições básicas que garantam a todos os espanhóis a igualdade no exercício dos direitos e cumprimento dos deveres constitucionais (artigo 149.1.1), das bases e coordenação do planeamento geral da atividade económica (artigo 149.1.13), das finanças gerais e dívida do Estado (artigo 149.1.14), e das bases do regime jurídico das administrações públicas e do procedimento administrativo comum (artigo 149.1.18).

\section{A PROPOSTA DE UMA RENDA BÁSICA UNIVERSAL}

Frente às limitações do IMV acima expostas, faz-se necessário considerar políticas alternativas que possam dar maior concreção aos mandamentos constitucionais pertinentes. É neste sentido que serão feitas algumas considerações comparativas entre a medida criada pelo Real Decreto-lei 20/2020 e o que seria uma Renda Básica Universal (RBU).

De acordo com a Basic Income Earth Network (BIEN), entende-se por RBU o pagamento periódico, em moeda corrente, em valor igual para todos, a título individual, sem exigência de comprovação de insuficiência de recursos ou cumprimento de quaisquer requisitos vinculados ao trabalho (BIEN, 2016). Disto decorrem 5 elementos que, de forma cumulativa, caracterizam a RBU: 1) 
regularidade, e não um pagamento único em determinado momento da vida; 2) em moeda corrente, e não pela entrega de bens ou prestação de serviços; 3) individualidade, e não em bases de estruturas coletivas, como a família, o lar ou a unidade de convivência; 4) universalidade, concedida a todos os indivíduos de determinada comunidade política independente de sua condição socioeconômica; e 5) incondicionalidade ${ }^{9}$, posto que não se exige daquele que a recebe que trabalhe, busque trabalho ou tenha qualquer nova conduta específica em relação à sua vida individual. Ainda que o IMV coincida com a RBU nos quesitos "1" e "2", dela se afasta no que se refere aos aspectos " 3 ", " 4 " e " 5 ", concentrando-se sobre estes as considerações a seguir.

Sobre o terceiro aspecto, o caráter individual, o IMV se distancia da RBU por seguir uma lógica de proteção do lar. Na prática, isso significa que um indivíduo membro de uma UC que conte, por exemplo, com cinco pessoas que atenderiam as condições de titularidade se individualmente consideradas, será apenas indiretamente beneficiado por uma pequena fração do IMV. Esta desproporção pode ainda ser agravada pela existência de estruturas de dominação internas à UC, fazendo com que muito pouco do auxílio, ou mesmo nada, chegue às pessoas que ocupem uma posição especialmente vulnerável dentro do grupo. Ademais, conforme já exposto, tal requisito dá ao Estado o poder de controle do indivíduo por meio de amplos mecanismos de verificação da composição familiar declarada. Aqui a autonomia, como elemento da dignidade humana, surge como fundamento de defesa do caráter individual da RBU frente ao formato coletivo do IMV.

Em virtude do quarto aspecto, ao contrário do que ocorre com o IMV, a universalidade faria com que a RBU alcançasse a íntegra dos residentes em Espanha, e não apenas os extremamente pobres. Há pelo menos duas consequências das ajudas direcionadas, não universais, que merecem ser questionadas ao se pensar uma estrutura de proteção social que preze pelos princípios constitucionais da eficiência (artigo 31) e do respeito à dignidade humana (artigo 10.1). Uma delas é o efetivo afastamento de qualquer hipótese da chamada armadilha da pobreza, posto que em nenhuma hipótese de alteração de sua renda ou de seu patrimônio o indivíduo deixará de receber a prestação estatal. A outra é a estigmatização dos beneficiários, formalmente identificados como pobres, com todas as consequências sociais e psicológicas que isto pode trazer.

O caráter universal da RBU, ao mesmo tempo em que é eficiente em seu objetivo de proteção social ao não desestimular o indivíduo a aceitar outras fontes de renda, preza pela sua dignidade, pois, uma vez que todos são igualmente titulares de um

\footnotetext{
9 Alguns autores, como VAN PARIJS; VANDERBORGHT (2017, p. 8), consideram a incondicionalidade como gênero do qual são espécies a individualidade, a universalidade e a ausência de obrigações. Para maior clareza analítica, o presente estudo trata sob o termo "incondicional" apenas a não imposição à pessoa de qualquer obrigação relacionada ao trabalho, à utilização do dinheiro recebido ou a qualquer nova conduta específica em sua vida individual.
} 
mesmo direito à RBU, nenhum é identificado perante os demais como necessitado de uma assistência social com ares de caridade.

A quinta característica, a incondicionalidade, faz com que a RBU não vincule a inserção social da pessoa ao emprego, ou ao qualquer outro projeto de vida imposto pelo Estado. Em sentido contrário, o IMV condiciona o seu recebimento à comprovação da condição de demandante de emprego, assim como à participação nas estratégias de inclusão social do Estado. O titular da RBU deve recebê-la porque possui constitucionalmente assegurada as suas dignidade e liberdade enquanto pessoa humana, e não para conquistar as condições materiais delas por meio do trabalho ou qualquer outra imposição.

De fato, parece bastante razoável, e em linha com o princípio constitucional da busca do pleno emprego (artigo 40.1), que os poderes públicos coloquem à disposição das pessoas ferramentas de inserção no mercado laboral. Entretanto, utilizá-las como condição necessária para que um ser humano tenha acesso aos recursos materiais mínimos para assegurar suas dignidade e liberdade real não parece se tratar de uma medida completamente alinhada com o mandamento do artigo 9.2 da CE/78.

Feitas tais considerações, estão sobre a mesa os instrumentos jurídicos para uma análise, sem pretensão exaustiva, das políticas públicas expostas e da sua adequação aos cenários presente e vindouros, na medida do que razoavelmente se pode predizer.

\section{CONSIDERAÇÕES FINAIS}

Mais de quatro décadas após a promulgação da CE/78 e com um significativo empurrão da pandemia de COVID-19 o Estado Social espanhol dá, com a criação do IMV, os primeiros passos firmes rumo a um sistema de proteção social realmente capaz de proteger de forma sistemática parte significativa daqueles afetados pelos problemas estruturais de pobreza e desemprego. Trata-se não de caridade, mas sim de criação de direitos para concreção a mandamentos constitucionais.

Entretanto, tal como uma criança que começa andar aos quatro anos idade, e empurrada por uma situação de profundo desespero, tais passos devem ser comemorados sem perder de vista que foram dados com significativo atraso, quer seja quando se compara com os vizinhos da União Europeia, quer seja quando se considera o nível de esgarçamento a que havia chegado a coesão do tecido social mesmo antes da pandemia.

O IMV, se implementado de maneira eficaz, significará a libertação de um significativo contingente populacional da pobreza extrema. Entretanto, imporá sobre tais pessoas rígido controle estatal e forte estigmatização social. Ademais, é insuficiente para tirar uma única pessoa espanhola da situação tecnicamente configurada de risco de pobreza. Neste sentido, o debate público deve seguir no sentido de aperfeiçoamento da estrutura de proteção social, considerando 
ferramentas que, como a RBU, atuem não como medidas assistenciais de combate à pobreza e controle social dos pobres, mas sim de justiça redistributiva capaz de assegurar a todas as pessoas a satisfação das necessidades materiais antes mesmo do evento da pobreza.

Antes que se afirme que a implementação de uma RBU em Espanha não seria economicamente viável, recomenda-se analisar as propostas de financiamento existentes, como a simulação segundo a qual a atribuição de tal prestação a todas as pessoas residentes em Espanha, com valor pelo menos igual ao umbral do risco de pobreza, levaria a uma sociedade mais igualitária, em que $80 \%$ da população mais pobre, comparada com a situação original, seria favorecida. Por óbvio, o custo de tal proposta seria uma reforma marcadamente progressiva da estrutura fiscal (ARCARONS; TORRENS; RAVENTÓS, 2017).

Como bem lembra a personagem de García Lorca citada na epígrafe, comer é necessário para viver. A liberdade de amarras impostas pelas privações materiais é necessária para que o indivíduo possa escolher e expressar de forma autônoma qual é, e qual não é, o seu lugar. Uma estrutura de proteção social que efetivamente busque superar a diferença entre liberdade e igualdade é a única capaz de dar concreção à fórmula do Estado Social, afastando a ideia de que certas pessoas não são constituídas da mesma substância jurídica que as demais. Não condicionar a liberdade real ao exercício de trabalho remunerado, assegurando-a de maneira anterior ao evento da pobreza, é essencial para que, em situações limítrofes, não se tenha que escolher entre manter a fonte de renda e chorar o luto de seus mortos, ou mesmo ser o motivo de luto de seus vivos.

\section{REFERÊNCIAS}

AIREF. Los Programas de Rentas Mínimas en España. Madrid: Autoridad Independiente de Responsabilidad Fiscal, 2019. Disponível em: <https://www.airef.es/wp-content/uploads/RENTA_MINIMA/20190626ESTUDIO-Rentas-minimas.pdf $>$.

ARCARONS, Jordi; TORRENS, Lluís; RAVENTÓS, Daniel. Renta básica incondicional: una propuesta de financiación racional y justa. Barcelona: Ediciones del Serbal, 2017.

ARGÜELLES BLANCO, Ana Rosa. La inclusión social mediante los programas autonómicos de rentas mínimas garantizadas. Estudios financieros. Revista de trabajo y seguridad social: Comentarios, casos prácticos: recursos humanos, n. 417, p. 125-162, 2017.

BASTIDA FREIJEDO, Francisco José. ¿Son los derechos sociales derechos fundamentales? In: ALEXY, Robert; GARCÍA MANRIQUE, Ricardo (Orgs.). 
Derechos sociales y ponderación. Madrid: Fundación Coloquio Jurídico Europeo, 2007, p. 103-149.

BERGANTIÑOS, Noemi; FONT QUILES, Raquel; BACIGALUPE, Amaia. Las rentas mínimas de inserción en época de crisis. ¿Existen diferencias en la respuesta de las comunidades autónomas? Papers, v. 102, p. 399-420, 2017. (3).

BIEN. About basic income. Basic Income Earth Network. Disponível em: <https://basicincome.org/basic-income/>. Acesso em: 11 abr. 2019.

COUNCIL OF EUROPE. Conclusions XXI-2 - Spain. Reporting system of the European Social Charter. Disponível em: <http://hudoc.esc.coe.int $>$. Acesso em: 30 mar. 2018.

COUNCIL OF THE EUROPEAN UNION. COM (2020) 509 - Council Recommendation on the 2020 National Reform Programme of Spain and delivering a Council opinion on the 2020 Stability Programme of Spain. Brussels: European Union, 2020.

DOMÉNECH, Rafael; GARCÍA, Juan Ramón; MONTAÑEZ, Miriam; et al. ¿Cuán vulnerable es el empleo en España a la revolución digital? Madrid: BBVA Research, 2018. (Observatório Econômico). Disponível em: $<$ https://www.bbvaresearch.com/publicaciones/cuan-vulnerable-es-el-empleo-enespana-a-la-revolucion-digital/>. Acesso em: 26 mar. 2018.

EUROSTAT. Gini coefficient of equivalised disposable income - EU-SILC survey. Eurostat Data Explorer. 2018a. Disponível em: $<$ http://appsso.eurostat.ec.europa.eu/nui/show.do?lang=en\&dataset=ilc_di12>. Acesso em: 28 mai. 2020.

EUROSTAT. Glossary: Monetary poverty. Eurostat. Statistics Explained. 2018b. Disponível em: <https://ec.europa.eu/eurostat/statisticsexplained/index.php?title=Glossary:Monetary_poverty>. Acesso em: 28 mai. 2020.

FUENMAYOR FERNÁNDEZ, Amadeo; GRANELL PÉREZ, Rafael. Las rentas mínimas de inserción autonómicas: simulación de sus efectos sobre la pobreza. In: Estado del bienestar: sostenibilidad y reformas. XX Encuentro de Economía Pública. Sevilla: Universidad de Sevilla, 2013, p. 1-36.

FUNDACIÓN FOESSA. VIII informe sobre exclusión y desarrollo social en España, 2019. Madrid: Cáritas Española Editores, 2019. 
GOBIERNO DE ESPAÑA. Estado de alarma crisis sanitaria COVID-19. Punto de Acceso General. 2020a. Disponível em:

$<$ https://administracion.gob.es/pag_Home/atencionCiudadana/Estado-de-alarmacrisis-sanitaria.html\#-5c02617e6a9c>. Acesso em: 29 mai. 2020.

GOBIERNO DE ESPAÑA. Presentación del Ingreso Mínimo Vital. Madrid:

Gobierno de España, 2020b. Disponível em:

$<$ https://www.lamoncloa.gob.es/consejodeministros/resumenes/Documents/2020/

290520-Ingreso-minimo-vital.pdf>. Acesso em: 29 maio 2020.

GOBIERNO DE ESPAÑA. Referencia del Consejo de Ministros (29/05/2020).

Madrid: Gobierno de España, 2020c. Disponível em:

$<$ https://www.lamoncloa.gob.es/consejodeministros/referencias/Paginas/2020/refc 20200529.aspx>. Acesso em: 29 maio 2020.

GOBIERNO DEL PRINCIPADO DE ASTURIAS. Evaluación Socioeconómica del Salario Social en Asturias. Evolución, perfiles, procesos de salida y retorno económico. Oviedo: Consejería de Servicios y Derechos Sociales del Principado de Asturias, 2017a. (Estudios e Investigaciones, 1).

GOBIERNO DEL PRINCIPADO DE ASTURIAS. Las Medidas de Incorporación Vinculadas al Salario Social Básico en Asturias. Situación, Evolución y Perspectivas. Oviedo: Consejería de Servicios y Derechos Sociales del Principado de Asturias, 2017b. (Estudios e Investigaciones, 2).

INE. Encuesta de condiciones de vida. Año 2018. Instituto Nacional de Estadística. 2018a. Disponível em:

$<$ https://www.ine.es/dyngs/INEbase/es/operacion.htm?c=Estadistica_C\&cid=1254 736176807\&menu=ultiDatos\&idp=1254735976608>. Acesso em: 29 mai. 2020.

INE. Encuesta de población activa. Instituto Nacional de Estadística. 2018b. Disponível em:

<https://www.ine.es/dyngs/INEbase/es/operacion.htm?c=Estadistica_C\&cid=1254 $736176918 \&$ menu $=$ resultados\&idp $=1254735976595 \#$ !tabs-1254736195129>. Acesso em: 29 mai. 2020.

INE. Indicadores de la Agenda 2030 para el Desarrollo Sostenible - Objetivo 1. Poner fin a la pobreza en todas sus formas y en todo el mundo. Instituto Nacional de Estadística. 2019. Disponível em: $<$ https://www.ine.es/dynt3/ODS/es/objetivo.htm?id=4836>. Acesso em: 29 mai. 2020. 
JIMENA QUESADA, Luis. Crónica de la jurisprudencia del Comité Europeo de Derechos Sociales - 2017. In: Revista Europea de Derechos Fundamentales. Granada: Editorial Comares, 2017, v. Digital, p. 1-41. Disponível em: <http://journals.sfu.ca/redf/index.php/redf/index>. Acesso em: 20 abr. 2018.

MERCADER UGUINA, Jesús R. Artículo 148.1.20. In: RODRÍGUEZ-PIÑERO, Miguel; CASAS BAAMONDE, María Emilia; ARNALDO ALCUBILLA, Enrique; et al (Orgs.). Comentarios a la Constitución española: XL aniversario. Madrid: Fundación Wolters Kluwer, Boletín Oficial del Estado, Tribunal Constitucional y Ministerio de Justicia, 2018, v. II.

MSCBS. Informe de Rentas Mínimas de Inserción - Año 2018. Madrid: Ministerio de Sanidad, Consumo y Bienestar Social, 2018. Disponível em: $<$ https://www.mscbs.gob.es/ssi/familiasInfancia/ServiciosSociales/RentasMinimas. htm>.

MTMSS. Afiliación al sistema con impacto de la COVID-19. Ministerio de Trabajo, Migraciones y Seguridad Social. Disponível em: $<$ http://prensa.mitramiss.gob.es/WebPrensa/noticias/seguridadsocial/detalle/3825 >. Acesso em: 4 jun. 2020.

PRESNO LINERA, Miguel Ángel. ¿De qué hablamos cuando hablamos de Derecho Constitucional? In: Una introducción cinematográfica al derecho, 2006, ISBN 84-8456-498-3, págs. 30-51. Valencia: Tirant lo Blanch, 2006, p. 30-51.

PSOE; UNIDAS PODEMOS. Coalición progresista. Un nuevo acuerdo para España. 2019. Disponível em: <https://podemos.info/coalicion-progresista/>. Acesso em: 20 abr. 2020.

ROCHA, Thiago Santos. O mínimo existencial na jurisprudência do Supremo Tribunal Federal. In: PORTELA, Irene Maria; GONÇALVES, Rubén Miranda; VEIGA, Fábio da Silva (Orgs.). Paradigmas do Direito Constitucional Atual. Barcelos: Instituto Politécnico do Cávado e do Ave, 2017, p. 313-323.

SALCEDO BELTRÁN, Maria Carmen. Incumplimientos por España de la Carta Social Europea. Conclusiones XX-2 (2013) del Comité Europeo de Derechos Sociales. Madrid: CCOO, 2014. (Colección Estudios F1M).

SARLET, Ingo Wolfgang; ZOCKUN, Carolina Zancaner. Notas sobre o mínimo existencial e sua interpretação pelo STF no âmbito do controle judicial das políticas públicas com base nos direitos sociais. Revista de Investigações Constitucionais, v. 3, n. 2, p. 115-141, 2016. 
STANDING, Guy. The precariat: the new dangerous class. London, UK; New York: Bloomsbury, 2014.

THE WORLD BANK. Country Poverty Brief - Brazil. Poverty \& Equity Data Portal. Disponível em: <http://povertydata.worldbank.org/poverty/country/BRA>. Acesso em: 1 abr. 2019.

VAN PARIJS, Philippe; VANDERBORGHT, Yannick. Basic Income: A Radical Proposal for a Free Society and a Sane Economy. London: Harvard University Press, 2017. 